\title{
Social Media or Personal Selling? Strategy for Successful Sales of Student Projects
}

\author{
Paula Sampson Ph.D., Ball State University, USA
}

Keywords: channel, communication, selling

The purpose of this project was to identify what method was most effective in converting potential customers into purchasers of student fashion products. It was student conducted research as a small part of a semester long class project.

Promotion is an important aspect of the fashion industry. In their careers, our graduates will be promoting their company product(s), promoting events and promoting themselves. The channels used to promote have greatly expanded with the introduction of the Internet and more recently social media. Students engage in a variety of activities where they may be promoting a product or an event as a part of their class work or club activities. So it is important to know what methods are the most effective for informing and for converting information into sales, both now and for their future careers.

Companies are exploring using social media and found them to be most useful at expanding networking and making personal contacts (Ferrell, L., Gonzales- Padron, T. L, and Ferrell, O.C., 2010). Companies also use social media to enhance their marketing schemes, for promotions, and to obtain data regarding their market's purchases and interests. Social media is the most effective when it is used on a continual basis once started. Although social media has value for marketing, in use it should be combined with traditional marketing and public relations. The primary disadvantages of social media related to privacy/security issues and scams/harassment (Hensel \& Deis, 2015).

Students enrolled in two courses with a semester long team project were used. The students in course one, designed, manufactured, marketed, and sold a textile product. In the class two the students planned and implemented a fashion show, selling tickets to the show. Both class projects were team based and the marketing teams collected the data. The students were encouraged to use multiple marketing channels. They put a lot of effort into using social media: Facebook, Tweeting, Instagram, etc. In addition they used flyer/posters, created a display (display case) and spoke to classes, friends and family about their project.

To determine how the individuals that purchased learned about the product/project, they were polled. In course one, students asked the buyer when the purchase was made and recorded it on the receipt kept by the class. In course two, show attendees were asked as they came into the show and it was recorded on a computer tablet. The purchasers ranged in age from college students to mature adults. In addition to the above formal data collection, data has also been collected informally in the last 5 years.

\section{Results}


For class one: The 122 respondents reported overwhelmingly that they learned about the show by word of mouth $98 \%(n=120)$ and $2 \%(n=2)$ learned via social media. The sample included diverse age groups, representing the families of many of the show participants. For class two: The 96 respondents favored person to person methods, with $86 \%(\mathrm{n}=83)$ using personal selling, and $8 \%$ using word of mouth $(\mathrm{n}=8)$. The remainder learned of the fashion product via indirect methods, $4 \%$ by social media $(n=4)$ and $1 \%$ by posted flyer $(n=1)$. Previous informal anecdotal information matched the formal data. Discussion

Recently, students have tended to use social media as the primary means of promoting projects. As this is a favored form of communication, this is not surprising. The marketing leaders from each class responded in their final report regarding the effectiveness of the advertising and promotion techniques they used. Using social media did encourage followers to some degree. However, overwhelmingly the people that purchased (product or ticket) did so because of a face-to face interaction with the seller. The manufacturing class (1) used Instagram, "but didn't get much engagement, so we decided to focus on Twitter." “... our Twitter account wasn't doing well and maybe people weren't following us or ordering from any social media." This group also had a Gmail account, "...but did not get any orders through the Gmail account." The fashion show class (2) reported statistics and then stated, "... it was a nice surprise to see the other forms of communication!" Limitations include, no means to purchase on line, sampling was done at a medium sized Midwest university, and the sample consisted of students, their family and friends.

It is informative for the students to note that interpersonal interaction may be more effective than less personal means such as social media. It too may depend on the age of the target market, as the younger generation has always had the option of seeking information and buying on-line, whereas more mature customers may have reservations, such as security. Social media may be good at informing, but when it comes to "closing the deal," personal interaction may be more effective. From student comments, it does not appear that their view of social media changed.

There was a lack of research in looking at the effectiveness of personal selling versus social media. Some of this may relate to how social media is used. Is it a public relations tool or a marketing tool? It is being used in both ways. For public relations and informational purposes, social media works well. The question remains for future study as to whether it also works as well as personal selling for closing the deal or selling. This research experience with discussion will continue as a part of these classes in the future.

\section{References}

Ferrell, L., Gonzales-Padron, T.L. and Ferrell, O. C. (Spring 2010). An assessment of the use of technology in the direct selling industry. Journal of Personal Selling \& Sales Management, XXX (2), 157-165.

Hensel, K., and Deis, M. H. (2010). Using social media to increase advertising and improve marketing. Entrepreneurial Executive 15, 87-98. 